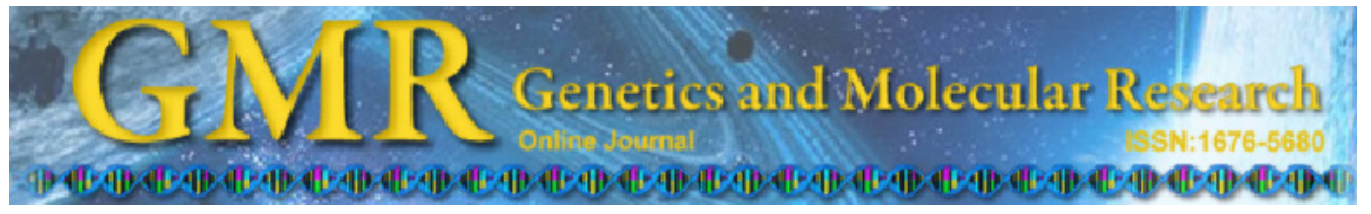

\title{
Association between CASP-8 gene polymorphisms and cancer risk in some Asian population based on a HuGE review and meta-analysis
}

\author{
Y.J. Zhang, X.P. Zhong, Y. Chen, S.R. Liu, G. Wu and Y.F. Liu \\ Department of General Surgery, First Affiliated Hospital of China Medical University, \\ Shenyang, Liaoning, China \\ Corresponding author: Y.F. Liu \\ E-mail: cmu1h_lyf@163.com \\ Genet. Mol. Res. 12 (4): 6466-6476 (2013) \\ Received May 21, 2012 \\ Accepted November 10, 2012 \\ Published February 28, 2013 \\ DOI http://dx.doi.org/10.4238/2013.February.28.3
}

\begin{abstract}
Genetic variation in the CASP-8 gene reportedly can increase cancer susceptibility by regulating tumor cell proliferation and apoptosis. Several studies have investigated this possibility; however, the conclusions remain controversial. We made a Human Genome Epidemiology (HuGE) review and did a meta-analysis to explore the association between CASP-8 gene polymorphisms and cancer risk in Asian populations. Based on the inclusion criteria, 12 case-control studies comprising 7720 cancer cases and 9404 healthy controls were retrieved. Meta-analysis results showed that the rs $3834129 *$ del allele/ carrier were associated with decreased risk of cancer in Asian populations [del allele: odd ratio $(\mathrm{OR})=0.79,95 \%$ confidence interval $(95 \% \mathrm{CI})=$ $0.75-0.83, \mathrm{P}<0.001$; del carrier: $\mathrm{OR}=0.77,95 \% \mathrm{CI}=0.72-0.82, \mathrm{P}<$ $0.001]$. Subgroup analysis showed that the rs $3834129 *$ del allele/carrier are protective factors for cancer risk in Chinese populations (del allele: $\mathrm{OR}=0.77,95 \% \mathrm{CI}=0.73-0.81, \mathrm{P}<0.001$; del carrier: $\mathrm{OR}=0.75,95 \% \mathrm{CI}$ $=0.70-0.80, \mathrm{P}<0.001)$, but not in Indian and Korean populations. Furthermore, the rs $6704688 * \mathrm{~T}$ allele/carrier, rs $3769827 * \mathrm{C}$ allele/carrier, rs $3769825^{*} \mathrm{C}$ allele/carrier were associated with decreased risk of cancer in Asian populations (all $\mathrm{P}<0.05$ ). While the rs $7608692 * \mathrm{~A}$ allele was
\end{abstract}


associated with increased risk of cancer risk in Asian populations (OR $=1.35,95 \% \mathrm{CI}=1.02-1.78, \mathrm{P}=0.03)$. There was also no significant association between rs3769818, rs13030042, rs13030042, rs1045494, rs1045494, rs2823, or rs 113686495, and cancer risk in Asian populations (all $\mathrm{P}>0.05$ ). This meta-analysis suggests that the rs $3834129 *$ del allele/ carrier, rs6704688*T allele/carrier, rs $3769827^{*} \mathrm{C}$ allele/carrier, and rs $3769825^{*} \mathrm{C}$ allele/carrier might be protective factors for cancer risk in Asian populations, while the rs7608692*A allele might be a risk factor for cancer risk in Asian populations.

Key words: Caspase 8; Genetic polymorphisms; Asian; Neoplasm; Meta-analysis

\section{INTRODUCTION}

Apoptosis is a fundamental biological process required to maintain the integrity and homeostasis of multicellular organisms, including normal cell turnover, the immune system, embryonic development, metamorphosis, and hormone-dependent atrophy, and in chemicalinduced cell death (Thompson, 1995). Early studies suggested that caspases may be responsible for some of the cellular changes associated with apoptosis (Cohen, 1997; Budihardjo et al., 1999). The apoptotic caspases are classified as initiators or executioners, depending on their point of entry into the apoptotic cascade (Shi, 2002; Boatright and Salvesen, 2003). Caspases-2, -8, -9, and -10 are apoptosis initiators; caspases-3, -6 , and -7 are apoptosis executors; caspase- $1,-4$, and -5 are involved in inflammation; and caspase-14 has a role in terminal differentiation of epidermal keratinocytes (Hengartner 2000; Boatright and Salvesen, 2003). Caspase-8 is essential for the extrinsic cell death pathways initiated by TNF family members (Danial and Korsmeyer, 2004). Activated caspase- 8 then initiates downstream apoptotic cascade by cleaving caspase-3 and/or caspase-7 (Budihardjo et al., 1999; Fan et al., 2005).

The consensus is that cancers are derived from numerous tissues with multiple etiologies, and tumor progression is accompanied by a bewildering and seemingly endless combination of genetic and epigenetic alterations, giving rise to a hugely disparate series of diseases (Evan and Vousden, 2001). Apoptotic malfunction plays an important role in cancer pathogenesis (Ghavami et al., 2009). Mutations within the caspase family of proteases are common in malignancies (Sellers and Fisher, 1999; Ghavami et al., 2009). Several reports have shown that CASP-8 is mutated in different types of cancers. Soung et al. (2005) found that the incidence of CASP-8 mutation in gastric cancer is statistically higher than in NSCLC, breast cancer, and acute leukemias. All mutants showed a significant reduction in CASP-8 activity in apoptosis when compared with wild-type CASP-8 (except mutation 1427T $>$ C) (Soung et al., 2005). A case-control study in a Chinese population found that the CASP-8 $-6526 \mathrm{~N} \mathrm{del} / \mathrm{del}$ exerted a multiplicative joint effect with FasL and Fas in attenuating susceptibility to pancreatic cancer (Yang et al., 2008). Nevertheless, these studies did not describe the precise relationship between CASP-8 and cancer risk in Asian populations, and disagreement on this issue remains. We performed a Human Genome Epidemiology (HuGE) review and meta-analysis by analyzing the most recent and relevant publications to identify statistical evidence of the association between CASP-8 gene polymorphisms and cancer risk in Asian populations. 


\section{MATERIAL AND METHODS}

\section{Identification of eligible studies}

PubMed, Cochrane Library, Embase, Web of Science, Springerlink, CNKI, and CBM databases were searched (last search was updated on May 10,2012) extensively to identify relevant studies. The search terms included ["caspase-8" or "CASP-8" or "Caspase 8" (Mesh)] and ["SNPs" or "SNP" or "polymorphism, genetic" (Mesh)] and ["cancer" or "tumor" or "Neoplasms" (Mesh)]. References in eligible studies or textbooks were also reviewed. The included studies had to meet the following criteria: the type of study should be a case-control study; the study must be focused on associations between CASP-8 polymorphisms and cancer risk in Asian populations; all patients must have the diagnosis of malignant tumor confirmed by pathological examination of a surgical specimen; the frequencies of alleles or genotypes in the case and control groups should be extracted; and the publication should be in English or Chinese. Studies were excluded when they were not case-control studies about CASP-8 polymorphisms and cancer risk in Asian populations; based on incomplete data; useless or overlapping data were reported.

\section{Data extraction}

Using a standardized form, data from published studies were extracted independently by two reviewers (Y.J.Z. and X.P.Z.) to collect information including first author, year of publication, country, language, ethnicity, study design, source of cases and controls, number of cases and controls, mean age, sample, pathological types, detection methods, polymorphism genotype frequency and evidence of Hardy-Weinberg equilibrium (HWE) in controls. In cases of conflicting evaluations, an agreement was reached following a discussion with a third reviewer (Y.F.L.).

\section{Quality assessment of included studies}

Two reviewers (Y.C. and S.R.L.) independently assessed the quality of the papers according to modified STROBE quality score systems (von Elm et al., 2007; Zhang et al., 2011). Forty quality appraisal items were used in this meta-analysis, with scores ranging from 0 to 40. Scores of 0-20, 20-30, and 30-40 were defined as low, moderate, and high quality, respectively. Disagreement was resolved by discussion.

\section{Statistical analysis}

Allele or genotype frequencies of CASP-8 SNPs were determined by the allele counting method. The odds ratio (OR) and $95 \%$ confidence interval $(95 \% \mathrm{CI})$ were calculated in Review Manager Version 5.1.6 (provided by the Cochrane Collaboration, available at: http:// ims.cochrane.org/revman/download) and STATA version 12.0 (Stata Corp., College Station, TX, USA). Between-study variations and heterogeneities were estimated using the Cochran Q-statistic (Zintzaras and Ioannidis, 2005; Peters et al., 2006) (P $\leq 0.05$ was considered to represent statistically significant heterogeneity). We also quantified the effect of heterogeneity by 
using a recently developed method called $\mathrm{I}^{2}$, which ranges from 0 to $100 \%$ and represents the proportion of inter-study variability that can be attributed to heterogeneity rather than chance. When a significant $\mathrm{Q}$-test $(\mathrm{P} \leq 0.05)$ or $\mathrm{I}^{2}>50 \%$ indicated heterogeneity, a random-effect model was generated for meta-analysis. Otherwise, the fixed-effect model was used. To establish the effect of heterogeneity on meta-analysis conclusions, subgroup analysis was performed. The $\chi^{2}$ test was used to determine whether the control genotype frequencies were in HWE. Funnel plots are often used to detect publication bias. However, due to limitations of varied sample size and subjective reviews, the Egger linear regression test (Higgins and Thompson, 2002), which measures the funnel plot asymmetry using a natural logarithm scale of OR, was used to evaluate publication bias. Publication bias was considered significant at $\mathrm{P}<0.1$.

\section{RESULTS}

\section{Characteristics of included studies}

We identified 105 relevant publications after the initial screen. According to the inclusion criteria, 12 publications (Ye, 2004; Son et al., 2006; Sun et al., 2007; Yang et al., 2008; Gangwar et al., 2009; Wang et al., 2009; Liu et al., 2010; Lv, 2010; Srivastava et al., 2010; Kesarwani et al., 2011; Ma et al., 2011; Xiao et al., 2011) appeared to have met the inclusion criteria and were subjected to further examination. A flow chart of study selection is shown in Figure 1. In total, 7720 cancer cases and 9404 healthy controls from 12 studies were included in the pooled analysis. Publication year ranged from 2004 to 2011. Overall, there were 3 lymphoma, 2 lung, 2 colorectal, 2 bladder, and 8 other cancer studies, including esophageal, gastric, prostate, breast, cervical, pancreatic, gallbladder, and ovarian cancers. Eight of these studies were conducted in China, 3 in India, and only 1 in Korea. The HWE test was conducted for the controls in every study; all were in HWE $(\mathrm{P}>0.05)$. All quality scores were $>20$ (moderate to high quality). The characteristics and methodological quality of the included studies are summarized in Table 1. Associations between CASP-8 polymorphisms and cancer risk in Asian populations are presented in Table 2.

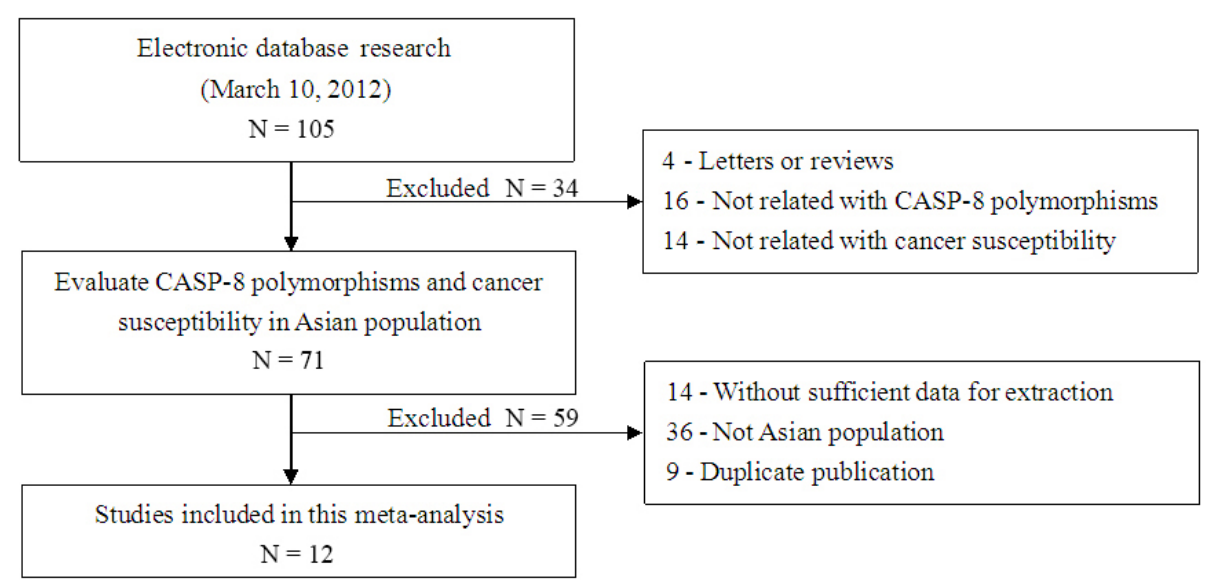

Figure 1. Flow chart shows study selection procedure. Twelve case-control studies were included in this meta-analysis. 
Table 1. Characteristics of individual studies in this meta-analysis.

\begin{tabular}{|c|c|c|c|c|c|c|c|}
\hline \multirow[t]{2}{*}{ Reference } & \multirow[t]{2}{*}{ Country } & \multicolumn{2}{|c|}{ Number } & \multirow{2}{*}{$\begin{array}{l}\text { Genotype } \\
\text { method }\end{array}$} & \multirow[t]{2}{*}{ Cancer type } & \multirow[t]{2}{*}{ SNPs } & \multirow{2}{*}{$\begin{array}{l}\text { Quality } \\
\text { scores }\end{array}$} \\
\hline & & Case & Control & & & & \\
\hline Ye, 2004 & China & 84 & 140 & PCR-DHPLC & Lymphoma & rs $2823(\mathrm{~A} / \mathrm{G})$ & 21 \\
\hline Son et al., 2006 & Korea & 432 & 432 & PCR-RFLP & Lung cancer & rs3834129 (del/ins), rs3769818 (G/A) & 27 \\
\hline Sun et al., 2007 & China & 4995 & 4972 & PCR-RFLP & Mixed cancers & rs3834129 (ins/del) & 23 \\
\hline Yang et al., 2008 & China & 397 & 907 & PCR-RFLP & Pancreatic cancer & rs3834129 (ins/del) & 24 \\
\hline Gangwar et al., 2009 & India & 212 & 250 & PCR-RFLP & Bladder cancer & rs3834129 (ins/del) & 29 \\
\hline Wang et al., 2009 & China & 365 & 368 & PCR-RFLP & Bladder cancer & rs3834129 (ins/del) & 26 \\
\hline Liu et al., 2010 & China & 373 & 838 & PCR-RFLP & Colorectal cancer & rs3834129 (ins/del), rs62514893 (A/G) & 25 \\
\hline Lv, 2010 & China & 100 & 544 & TaqMan & Lymphoma & rs3834129 (ins/del) & 26 \\
\hline Srivastava et al., 2010 & India & 230 & 230 & PCR-RFLP & Gallbladder cancer & $\begin{array}{l}\text { rs3834129 (ins/del), rs1045485 (G/C), } \\
\text { rs3769818 (G/A) }\end{array}$ & 24 \\
\hline Kesarwani et al., 2011 & India & 175 & 198 & PCR-RFLP & Prostate cancer & rs3834129 (ins/del) & 24 \\
\hline Ma et al., 2011 & China & 218 & 285 & Mass-Array & Ovarian cancer & $\begin{array}{l}\text { rs3834129 (ins/del), rs3769827 (T/C), } \\
\text { rs3769825 (T/C), rs13030042 (T/C), } \\
\text { rs1045494 (T/C), rs6704688 (C/T), } \\
\text { rs3769818 (G/A), rs7608692 (G/A) }\end{array}$ & 22 \\
\hline Xiao et al., 2011 & China & 139 & 240 & PCR-RFLP & Lymphoma & $\begin{array}{l}\text { rs3834129 (ins/del), rs3769821 (T/C), } \\
\text { rs113686495 (ins/del) }\end{array}$ & 28 \\
\hline
\end{tabular}

$\overline{\mathrm{PCR}}=$ polymerase chain reaction; DHPLC $=$ denaturing high-performance liquid chromatography; SNPs = single nucleotide polymorphisms; RFLP = restriction fragment length polymorphism.

Table 2. Association between polymorphisms of the CASP-8 gene and cancer susceptibility in Asian population.

\begin{tabular}{|c|c|c|c|c|c|c|c|c|}
\hline \multirow[t]{2}{*}{ Polymorphisms } & & \multirow[t]{2}{*}{ Case $(\mathrm{n} / \mathrm{N})$} & \multirow[t]{2}{*}{ Control (n/N) } & \multirow[t]{2}{*}{ OR $(95 \% \mathrm{CI})$} & \multirow[t]{2}{*}{$\mathrm{P}$} & \multicolumn{2}{|c|}{ Heterogeneity } & \multirow[t]{2}{*}{ Effect model } \\
\hline & & & & & & $\mathrm{P}$ & $\mathrm{I}^{2}$ & \\
\hline \multirow[t]{2}{*}{ rs3834129 (ins/del) } & del allele & $3105 / 15138$ & $4497 / 18146$ & $0.79(0.75-0.83)$ & $<0.001$ & $<0.001$ & $79 \%$ & Random \\
\hline & del carrier & $2788 / 7569$ & $3936 / 9208$ & $0.77(0.72-0.82)$ & $<0.001$ & $<0.001$ & $73 \%$ & \\
\hline \multirow[t]{2}{*}{ rs3769818 (G/A) } & A allele & $421 / 1754$ & $444 / 1890$ & $1.03(0.88-1.20)$ & 0.69 & 0.47 & $0 \%$ & Fixed \\
\hline & A carrier & $371 / 877$ & $381 / 945$ & $1.09(0.90-1.32)$ & 0.38 & 0.64 & $0 \%$ & \\
\hline \multirow{2}{*}{ rs62514893 (A/G) } & $\mathrm{G}$ allele & $222 / 738$ & $475 / 1676$ & $1.09(0.90-1.32)$ & 0.38 & - & - & Fixed \\
\hline & G carrier & $188 / 369$ & $405 / 838$ & $1.11(0.87-1.42)$ & 0.40 & - & - & \\
\hline \multirow[t]{2}{*}{ rs13030042 (T/C) } & $\mathrm{C}$ allele & $113 / 436$ & $140 / 570$ & $1.07(0.81-1.43)$ & 0.62 & - & - & Fixed \\
\hline & $\mathrm{C}$ carrier & $94 / 218$ & $121 / 285$ & $1.03(0.72-1.47)$ & 0.88 & - & - & \\
\hline \multirow[t]{2}{*}{ rs7608692 (G/A) } & A allele & $137 / 436$ & $144 / 568$ & $1.35(1.02-1.78)$ & 0.03 & - & - & Fixed \\
\hline & A carrier & $111 / 218$ & $122 / 284$ & $1.38(0.97-1.96)$ & 0.08 & - & - & \\
\hline \multirow[t]{2}{*}{ rs6704688 (C/T) } & $\mathrm{T}$ allele & $104 / 436$ & $182 / 568$ & $0.66(0.50-0.88)$ & 0.004 & - & - & Fixed \\
\hline & $\mathrm{T}$ carrier & $93 / 218$ & $147 / 284$ & $0.69(0.49-0.99)$ & 0.04 & - & - & \\
\hline \multirow[t]{2}{*}{ rs3769821 (T/C) } & $\mathrm{C}$ allele & $94 / 278$ & $148 / 480$ & $1.15(0.84-1.57)$ & 0.40 & - & - & Fixed \\
\hline & $\mathrm{C}$ carrier & $81 / 139$ & $126 / 240$ & $1.26(0.83-1.93)$ & 0.28 & - & - & \\
\hline \multirow[t]{2}{*}{ rs3769827 (T/C) } & $\mathrm{C}$ allele & $97 / 436$ & $181 / 570$ & $0.61(0.46-0.82)$ & $<0.001$ & - & - & Fixed \\
\hline & $\mathrm{C}$ carrier & $92 / 218$ & $153 / 285$ & $0.63(0.44-0.90)$ & 0.01 & - & - & \\
\hline \multirow[t]{2}{*}{ rs3769825 (T/C) } & $\mathrm{C}$ allele & $91 / 434$ & $151 / 570$ & $0.74(0.55-0.99)$ & 0.04 & - & - & Fixed \\
\hline & $\mathrm{C}$ carrier & $83 / 217$ & $132 / 285$ & $0.72(0.50-1.03)$ & 0.07 & - & - & \\
\hline \multirow[t]{2}{*}{ rs1045494 (T/C) } & $\mathrm{C}$ allele & $110 / 436$ & $133 / 570$ & $1.11(0.83-1.48)$ & 0.49 & - & - & Fixed \\
\hline & $\mathrm{C}$ carrier & $91 / 218$ & $114 / 285$ & $1.07(0.75-1.54)$ & 0.69 & - & - & \\
\hline \multirow[t]{2}{*}{ rs1045494 (G/C) } & $\mathrm{C}$ allele & $24 / 454$ & $19 / 460$ & $1.30(0.70-2.40)$ & 0.41 & - & - & Fixed \\
\hline & $\mathrm{C}$ carrier & $23 / 227$ & $18 / 230$ & $1.33(0.70-2.53)$ & 0.39 & - & - & \\
\hline \multirow[t]{2}{*}{ rs2823 (A/G) } & G allele & $29 / 168$ & $52 / 280$ & $0.91(0.55-1.51)$ & 0.73 & - & - & Fixed \\
\hline & G carrier & $25 / 84$ & $49 / 140$ & $0.79(0.44-1.41)$ & 0.42 & - & - & \\
\hline \multirow[t]{2}{*}{ rs113686495 (ins/del) } & del allele & $188 / 278$ & $348 / 480$ & $0.79(0.57-1.09)$ & 0.16 & - & - & Fixed \\
\hline & del carrier & $127 / 139$ & $219 / 240$ & $1.01(0.48-2.13)$ & 0.97 & - & - & \\
\hline
\end{tabular}

$\mathrm{OR}=$ odd ratio $; 95 \% \mathrm{CI}=95 \%$ confidence interval.

\section{rs3834129 of the CASP-8 gene and cancer risk}

The meta-analysis results showed that the rs $3834129 *$ del allele/carrier were associated 
with decreased risk of cancer in the Asian populations (del allele: $\mathrm{OR}=0.79,95 \% \mathrm{CI}=0.75$ $0.83, \mathrm{P}<0.001$; del carrier: $\mathrm{OR}=0.77,95 \% \mathrm{CI}=0.72-0.82, \mathrm{P}<0.001)$. In the subgroup analysis by country, we found that the rs $3834129 *$ del allele/carrier were protective factors for cancer risk in Chinese populations (del allele: $\mathrm{OR}=0.77,95 \% \mathrm{CI}=0.73-0.81, \mathrm{P}<0.001$; del carrier: $\mathrm{OR}=0.75,95 \% \mathrm{CI}=0.70-0.80, \mathrm{P}<0.001)$. However, there was no significant association between rs3834129 and cancer risk in Indian and Korean populations (all P > 0.05). Associations between rs3834129 (ins/del) and cancer risk in Asian populations are shown in Figure 2.

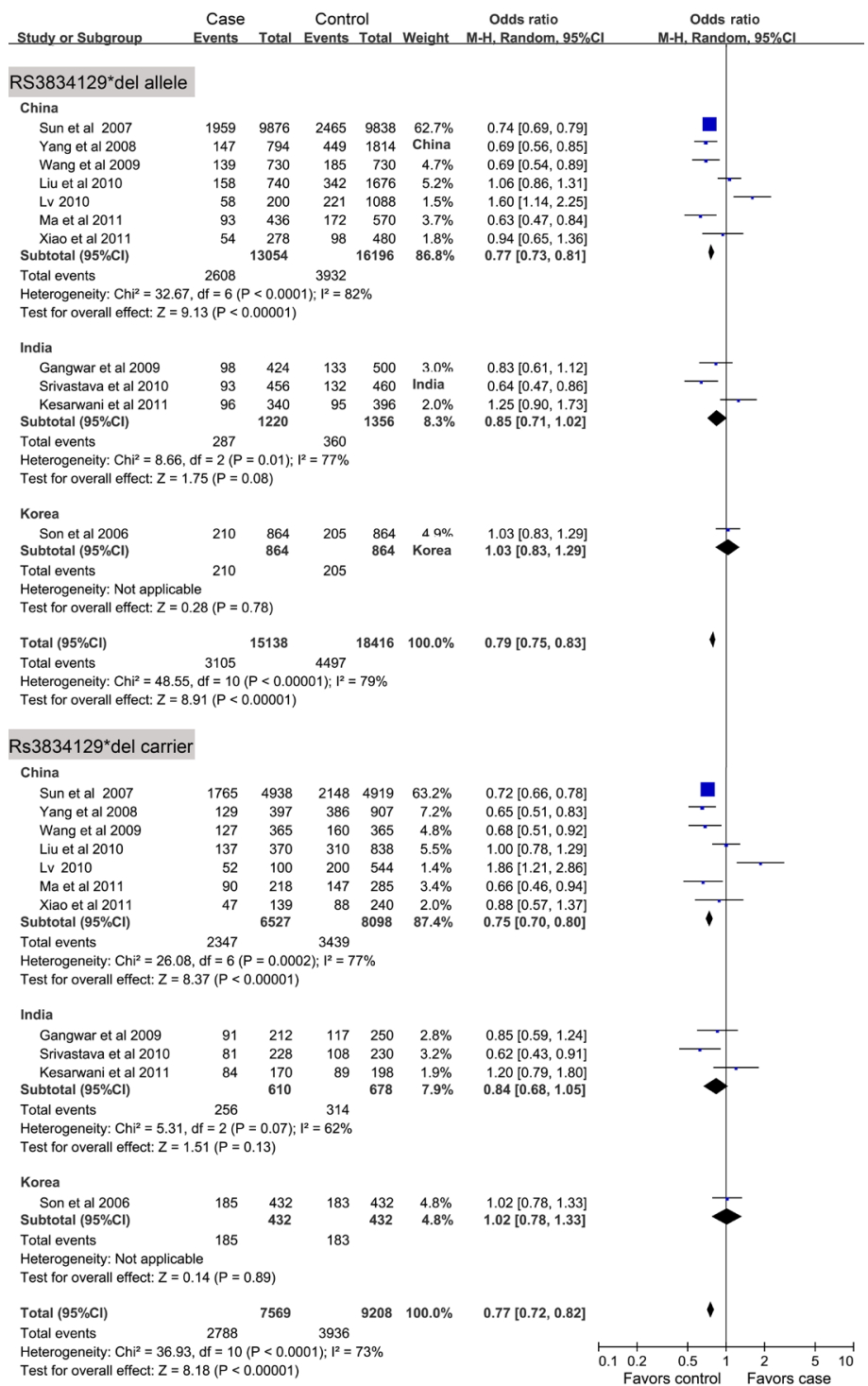

Figure 2. Associations between rs3834129 (ins/del) of the CASP-8 gene and cancer risk in Asian population. $95 \% \mathrm{CI}=$ confidence interval; d.f. $=$ degrees of freedom; $\mathrm{M}-\mathrm{H} .=$ Mantel-Haenszel estimator. 


\section{rs3769818 and cancer risk}

There was no association between the rs $3769818 * \mathrm{~A}$ allele/carrier and cancer risk in Asian populations (A allele: $\mathrm{OR}=1.03,95 \% \mathrm{CI}=0.88-1.20, \mathrm{P}=0.69$; A carrier: $\mathrm{OR}=1.09$, $95 \% \mathrm{CI}=0.90-1.32, \mathrm{P}=0.38)$. We also found no association in the subgroup analysis by country (all $\mathrm{P}>0.05)$. Associations between rs $3769818(\mathrm{G} / \mathrm{A})$ and cancer risk in Asian populations are shown in Figure 3.

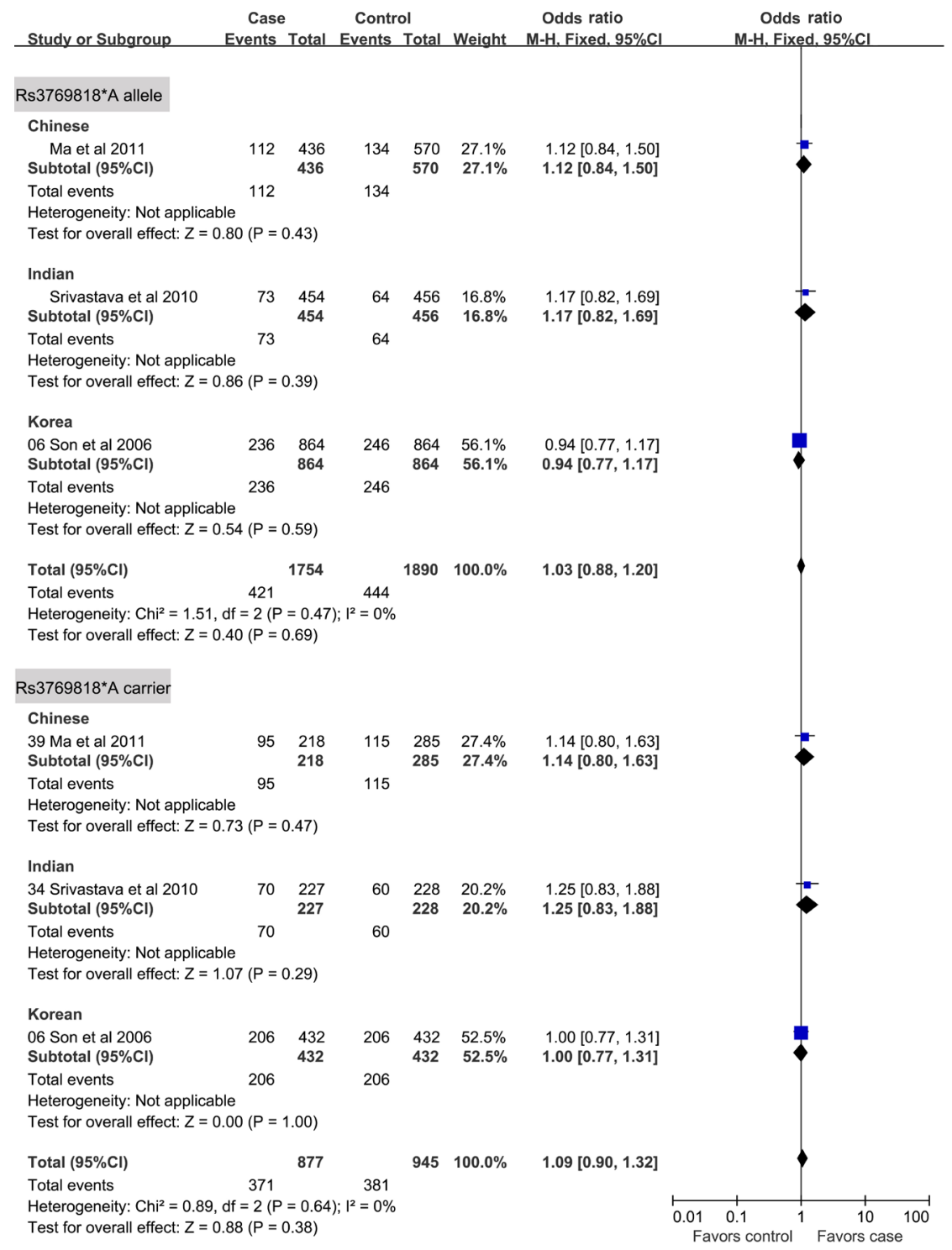

Figure 3. Associations between rs 3769818 (G/A) of the CASP-8 gene and cancer risk in Asian population. For abbreviations, see legend to Figure 2. 


\section{Other CASP-8 polymorphisms and cancer risk}

In addition (as shown in Table 2), the rs6704688*T allele/carrier, rs $3769827^{*} \mathrm{C}$ allele/carrier, rs $3769825^{*} \mathrm{C}$ allele/carrier were associated with decreased risk of cancer in Asian populations. The rs $7608692 * \mathrm{~A}$ allele was associated with increased cancer risk $(\mathrm{OR}=1.35,95 \% \mathrm{CI}=1.02-1.78, \mathrm{P}=0.03)$. We found no significant association between rs3769818, rs13030042, rs13030042, rs1045494, rs1045494, rs2823, or rs 113686495 and cancer risk in Asian populations. Given the relatively small sample size, further subgroup analysis was not conducted.

\section{Publication bias}

Publication bias of the literature was accessed based on rs $3834129 *$ del allele/carrier and rs3769818*A allele/carrier by Begger's funnel plot and the Egger linear regression test. The Egger linear regression test was used to measure the asymmetry of the funnel plot. All graphical funnel plots appeared to be symmetrical (Figure 4). The Egger test also showed no statistical significance for all evaluations of publication bias (all $\mathrm{P}>0.05$ ). The findings of the Egger publication bias test are shown in Table 3.
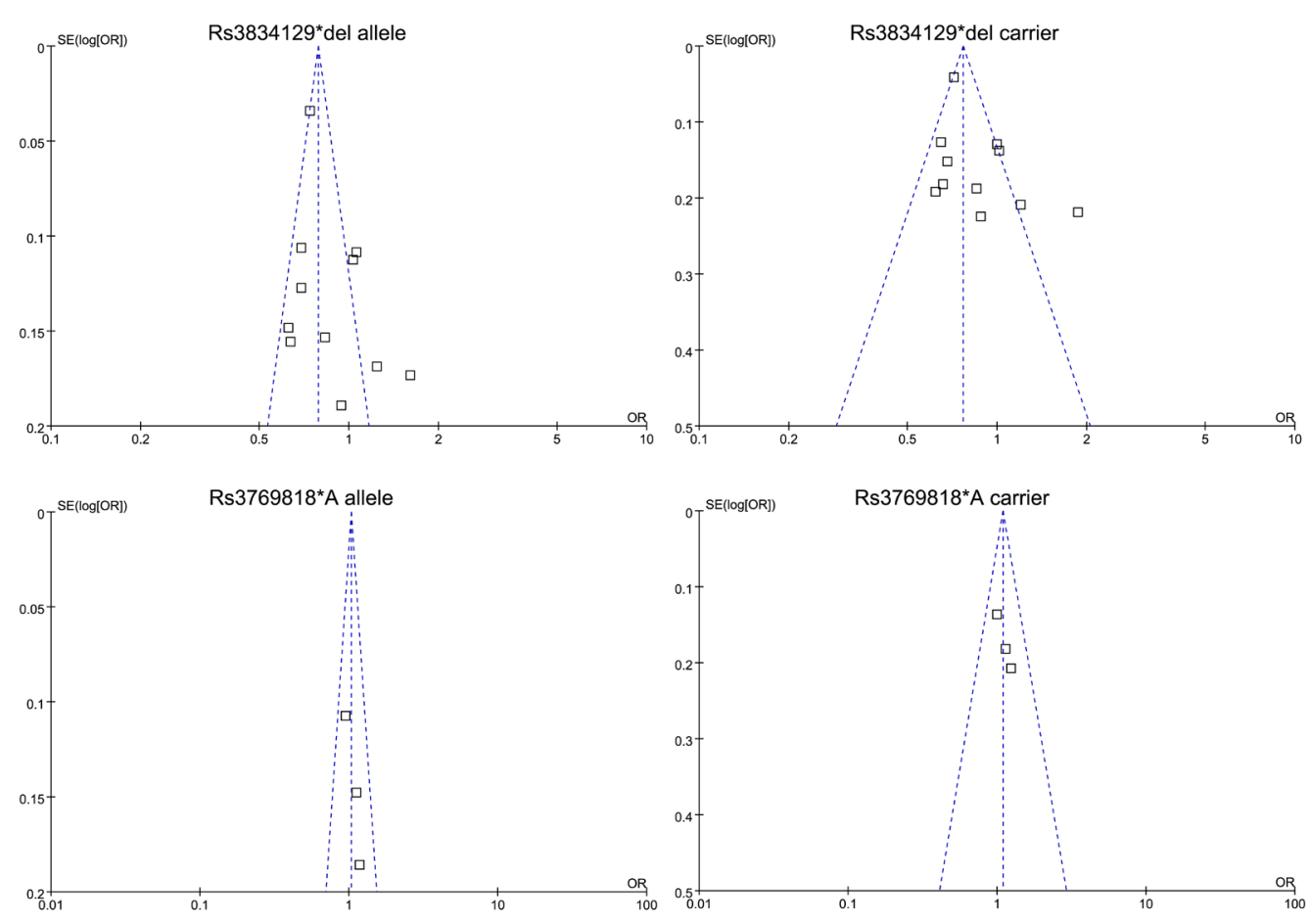

Figure 4. Begger's funnel plot of publication bias based on rs3834129 and rs3769818. SE = standard error; $\mathrm{OR}=$ odds ratio. 
Table 3. Evaluation of publication bias by the Egger linear regression test.

\begin{tabular}{lccccc}
\hline SNP & Coefficient & SE & $t$ & P & $95 \%$ CI \\
\hline rs3834129*del allele & 1.690 & 1.082 & 1.560 & 0.153 & {$[-0.758-4.138]$} \\
rs3834129*del carrier & 1.584 & 0.914 & 1.730 & 0.117 & {$[-0.484-3.653]$} \\
rs3769818*A allele & 3.065 & 0.901 & 3.400 & 0.182 & {$[-8.381-14.512]$} \\
rs3769818*A carrier & 3.036 & 0.137 & 22.180 & 0.029 & {$[1.297-4.775]$} \\
\hline
\end{tabular}

$\mathrm{SE}=$ standard error; $95 \% \mathrm{CI}=95 \%$ confidence interval.

\section{DISCUSSION}

Since the recognition of the originally named interleukin-1 beta-converting enzyme, (ICE) or caspase-1 in 1993, additional 17 related ICE-like caspase proteases have been identified (Fan et al., 2005; Chowdhury et al., 2008). Proteases of the caspase family play central roles in apoptosis and inflammation (Creagh et al., 2003; Fan et al., 2005). In humans, the caspase family includes 14 proteins with a peptidase C14 domain: caspase- $1,-2,-3,-4,-5,-6,-7,-8,-9,-10$, -12, and -14; CLFAR (CASP-8 and FADD-like apoptosis regulator, c-FLIP); and the product of the mucosa-associated lymphoid tissue lymphoma translocation gene 1 (Fan et al., 2005; Pereira and Amarante-Mendes, 2011). Caspase activation is fundamentally important in cell death commitment, and substantial efforts have been devoted to understanding the underlying mechanisms of this process (Kumar, 2004; Kumar and Dorstyn, 2009). Once activated, initiator caspases process and activate effector caspases, which then mediate cleavage of a wide range of vital cellular proteins, producing characteristic cellular morphological changes such as membrane blebbing, nuclear condensation, DNA fragmentation, and ultimately the demise of the cell (Jin and El-Deiry, 2005; Cheung et al., 2006). Inappropriate apoptosis, however, underlies the etiology of many of the most intractable of human diseases, including neurodegenerative diseases such as Alzheimer's and Huntington's, ischemic damage, autoimmune disorders, and several forms of cancer (Cohen, 1997; Evan and Vousden, 2001; Johnstone et al., 2002).

A large multi-ethnic cohort study of 11,391-18,290 cases and 14,753-22,670 controls found evidence of an association between breast cancer and the CASP-8 D302H variant (Cox et al., 2007). Rajaraman et al. (2007) confirmed the association between 2 common CASP-8 variants and significantly increased risk of meningioma. Hypermethylation of CASP-8 has been linked to glioblastoma multiform relapse, suggesting that caspase- 8 may have a role in the development of glioma (Martinez et al., 2007). However, a multi-center epidemiological case-control study was not consistent with other published data on meningioma that showed increased risk of CASP-8 D302H variant in meningioma (Bethke et al., 2009). This controversy might be due to the different populations and ethnicities of the studies. In this metaanalysis of 7720 cancer cases and 9404 healthy controls from 12 independent studies, we examined the association of 13 CASP-8 polymorphisms and cancer risk in Asian populations. We demonstrated that del allele and del carrier of rs3834129 (ins/del) had negative associations with cancer susceptibility in Asian populations, with rs3834129 providing protection against cancer development, probably because of the powerful and effective immune surveillance of malignant cells by T-lymphocytes. Ethnicity may influence cancer susceptibility through variations in genetic backgrounds and environmental exposure leading to various gene-gene and gene-environment interactions. Subgroup analysis showed that del allele and del carrier of rs3834129 were protective in Chinese, but not in Indian and Korean groups. No 
associations were demonstrated between rs3769818 (G/A) and cancer susceptibility in Asians. Contrary to our expectations, we also found no association between rs3834129 and the subgroup analysis of cancer risk, including Chinese, Indian, and Korean groups. Concerning other polymorphisms of the CASP-8 gene, this meta-analysis is consistent with these previous studies cited, which were performed on a smaller number of subjects. It is worth mentioning that rs6704688, rs3769827, and rs3769825 are associated with reduced cancer risk. In addition, the many limitations in our meta-analysis should be addressed. First, the relevant research articles are few and the sample size was not large. In addition, some relevant studies were included due to incomplete raw data. Third, we were not able to address the sources of heterogeneity in all studies. Fourth, although all cases and controls were well defined with similar inclusion criteria, there may be factors that were not taken into account that may have influenced our results. Most important, our meta-analysis was based on unadjusted OR estimates because not all publications presented adjusted ORs and when they did, the ORs were not adjusted by the same potential confounders, such as ethnicity, gender, geographic distribution, etc. Given these results, additional investigation in these areas is needed, and our conclusions should be interpreted cautiously.

In conclusion, this meta-analysis of 12 case-control studies demonstrated that the CASP-8 gene polymorphisms are involved with the pathogenesis of cancer. The del allele and del carrier of rs3834129 might be protective against cancer in Asian populations. As few studies are available in this field and evidence remains limited, we emphasize the necessity to conduct large studies with adequate methodological quality and proper control of confounding factors to obtain valid results.

\section{ACKNOWLEDGMENTS}

We would like to thank Liu Jia-Li (Department of Oncology, Yueyang First People's Hospital) for his valuable contribution and for kindly revising the manuscript.

\section{REFERENCES}

Bethke L, Sullivan K, Webb E, Murray A, et al. (2009). CASP8 D302H and meningioma risk: an analysis of five casecontrol series. Cancer Lett. 273: 312-315.

Boatright KM and Salvesen GS (2003). Mechanisms of caspase activation. Curr. Opin. Cell Biol. 15: 725-731.

Budihardjo I, Oliver H, Lutter M, Luo X, et al. (1999). Biochemical pathways of caspase activation during apoptosis. Annu. Rev. Cell Dev. Biol. 15: 269-290.

Cheung HH, Arora V and Korneluk RG (2006). Abnormalities of cell structures in tumors: apoptosis in tumors. EXS 96: 201221.

Chowdhury I, Tharakan B and Bhat GK (2008). Caspases - an update. Comp. Biochem. Physiol. B Biochem. Mol. Biol. 151: $10-27$.

Cohen GM (1997). Caspases: the executioners of apoptosis. Biochem. J. 326 (Pt 1): 1-16.

Cox A, Dunning AM, Garcia-Closas M, Balasubramanian S, et al. (2007). A common coding variant in CASP8 is associated with breast cancer risk. Nat. Genet. 39: 352-358.

Creagh EM, Conroy H and Martin SJ (2003). Caspase-activation pathways in apoptosis and immunity. Immunol. Rev. 193: 10-21.

Danial NN and Korsmeyer SJ (2004). Cell death: critical control points. Cell 116: 205-219.

Evan GI and Vousden KH (2001). Proliferation, cell cycle and apoptosis in cancer. Nature 411: 342-348.

Fan TJ, Han LH, Cong RS and Liang J (2005). Caspase family proteases and apoptosis. Acta Biochim. Biophys. Sin. (Shanghai) 37: 719-727.

Gangwar R, Mandhani A and Mittal RD (2009). Caspase 9 and caspase 8 gene polymorphisms and susceptibility to 
bladder cancer in north Indian population. Ann. Surg. Oncol. 16: 2028-2034.

Ghavami S, Hashemi M, Ande SR, Yeganeh B, et al. (2009). Apoptosis and cancer: mutations within caspase genes. $J$. Med. Genet. 46: 497-510.

Hengartner MO (2000). The biochemistry of apoptosis. Nature 407: 770-776.

Higgins JP and Thompson SG (2002). Quantifying heterogeneity in a meta-analysis. Stat. Med. 21: 1539-1558.

Jin Z and El-Deiry WS (2005). Overview of cell death signaling pathways. Cancer Biol. Ther. 4: 139-163.

Johnstone RW, Ruefli AA and Lowe SW (2002). Apoptosis: a link between cancer genetics and chemotherapy. Cell 108: 153-164.

Kesarwani P, Mandal RK, Maheshwari R and Mittal RD (2011). Influence of caspases 8 and 9 gene promoter polymorphism on prostate cancer susceptibility and early development of hormone refractory prostate cancer. BJU Int. 107: 471-476.

Kumar S (2004). Measurement of caspase activity in cells undergoing apoptosis. Methods Mol. Biol. 282: 19-30.

Kumar S and Dorstyn L (2009). Analysing caspase activation and caspase activity in apoptotic cells. Methods Mol. Biol. 559: 3-17.

Liu B, Zhang Y, Jin M, Ni Q, et al. (2010). Association of selected polymorphisms of CCND1, p21, and caspase8 with colorectal cancer risk. Mol. Carcinog. 49: 75-84.

Lv Z (2010). Genetic Polymorphisms in CASP8, Fas and Fas Ligand and the Risk of Peripheral T-cell Lymphoma and the Relationship Between the Genetic Polymorphisms and the Clinical Characteristics and Prognosis. Doctoral thesis, Peking Union Medical College, Beijing.

Ma X, Zhang J, Liu S, Huang Y, et al. (2011). Polymorphisms in the CASP8 gene and the risk of epithelial ovarian cancer. Gynecol. Oncol. 122: 554-559.

Martinez R, Setien F, Voelter C, Casado S, et al. (2007). CpG island promoter hypermethylation of the pro-apoptotic gene caspase-8 is a common hallmark of relapsed glioblastoma multiforme. Carcinogenesis 28: 1264-1268.

Pereira WO and Amarante-Mendes GP (2011). Apoptosis: a programme of cell death or cell disposal? Scand. J. Immunol. 73: 401-407.

Peters JL, Sutton AJ, Jones DR, Abrams KR, et al. (2006). Comparison of two methods to detect publication bias in metaanalysis. JAMA 295: 676-680.

Rajaraman P, Wang SS, Rothman N, Brown MM, et al. (2007). Polymorphisms in apoptosis and cell cycle control genes and risk of brain tumors in adults. Cancer Epidemiol. Biomarkers Prev. 16: 1655-1661.

Sellers WR and Fisher DE (1999). Apoptosis and cancer drug targeting. J. Clin. Invest. 104: 1655-1661.

Shi Y (2002). Mechanisms of caspase activation and inhibition during apoptosis. Mol. Cell 9: 459-470.

Son JW, Kang HK, Chae MH, Choi JE, et al. (2006). Polymorphisms in the caspase-8 gene and the risk of lung cancer. Cancer Genet. Cytogenet. 169: 121-127.

Soung YH, Lee JW, Kim SY, Jang J, et al. (2005). CASPASE-8 gene is inactivated by somatic mutations in gastric carcinomas. Cancer Res. 65: 815-821.

Srivastava K, Srivastava A and Mittal B (2010). Caspase-8 polymorphisms and risk of gallbladder cancer in a northern Indian population. Mol. Carcinog. 49: 684-692.

Sun T, Gao Y, Tan W, Ma S, et al. (2007). A six-nucleotide insertion-deletion polymorphism in the CASP8 promoter is associated with susceptibility to multiple cancers. Nat. Genet. 39: 605-613.

Thompson CB (1995). Apoptosis in the pathogenesis and treatment of disease. Science 267: 1456-1462.

von Elm E, Altman DG, Egger M, Pocock SJ, et al. (2007). The Strengthening the Reporting of Observational Studies in Epidemiology (STROBE) statement: guidelines for reporting observational studies. Epidemiology 18: 800-804.

Wang M, Zhang Z, Tian Y, Shao J, et al. (2009). A six-nucleotide insertion-deletion polymorphism in the CASP8 promoter associated with risk and progression of bladder cancer. Clin. Cancer Res. 15: 2567-2572.

Xiao MS, Zhang DF, Zeng Y, Cheng YF, et al. (2011). Polymorphisms in the promoter region of the CASP8 gene are not associated with non-Hodgkin's lymphoma in Chinese patients. Ann. Hematol. 90: 1137-1144.

Yang M, Sun T, Wang L, Yu D, et al. (2008). Functional variants in cell death pathway genes and risk of pancreatic cancer. Clin. Cancer Res. 14: 3230-3236.

Ye YF (2004). Polymorphisms of Caspase-8, -10 Genes and Their Relationship with Pathogenesis of Non-Hodgkin Lymphoma. Zhejiang University, Hangzhou.

Zhang L, Liu JL, Zhang YJ and Wang H (2011). Association between HLA-B*27 polymorphisms and ankylosing spondylitis in Han populations: a meta-analysis. Clin. Exp. Rheumatol. 29: 285-292.

Zintzaras E and Ioannidis JP (2005). Heterogeneity testing in meta-analysis of genome searches. Genet. Epidemiol. 28: 123-137. 